\title{
Erotografia poética de E. M. de Melo e Castro E. M. de Melo e Castro's poetical erotography
}

Resumo: A poesia de E. M. de Melo e Castro dialoga com o princípio do ideograma e com aspectos da lírica tradicional japonesa, como a concisão, visualidade e montagem, incorporados de maneira crítica e criativa, sob uma perspectiva de vanguarda.

Palavras-chave: Haicai, ideograma, concretismo, experimentalismo.

Abstract: E. M. de Melo e Castro's poetry connects with the ideogram concept and with traditional lyrical Japanese aspects such as conciseness, visual identity and a collage of ideas incorporated in a critical and creative way under vanguardism.

Keywords: Haicai, ideogram, concretism, experimentalism.

* Universidade de São Paulo (USP). 
rnesto Manuel Geraldes de Melo e Castro (1932), que assina sua obra poética, ficcional, teórica e ensaística como E. M. de Melo e Castro, foi um dos expoentes do movimento da Poesia Experimental (PO-EX) na década de 1960, ao lado de Ana Hatherly, Salette Tavares, Antônio Aragão e Herberto Helder. Comentaremos, neste artigo, a ressonância da estética do ideograma em sua produção textual, a presença da visualidade e da justaposição de signos em sua poesia, além do diálogo criativo com o haicai, remodelado pelo autor numa estrutura de quatro versos e temática erótica, em dissonância com a quase ausência do elemento amoroso no haicai tradicional - o tema erótico-amoroso será mais frequente na poesia japonesa a partir da Restauração Meiji, destacando-se a produção de Yosano Akiko (1878-1942), autora de versos como estes, traduzidos por Donatella Natili e Álvaro Faleiros: "ouça o poema / como negar o carmim / da flor do campo? / delícias a menina / pecar na primavera" (Akiko, 2007: 53). No livro Ideogramas, publicado em 1962, Melo e Castro reúne 29 poemas concretos, publicados sem qualquer introdução ou nota explicativa; este é o marco zero da Poesia Concreta e do Experimentalismo em Portugal ${ }^{1}$ (embora seja possível rastrearmos uma pré-história da visualidade na poesia portuguesa na época maneirista e barroca, tema estudado por Ana Hatherly em A experiência

1 O poeta concretista brasileiro Pedro Xisto (ele próprio estudioso da cultura japonesa e autor de numerosos haicais) escreveu uma carta a Melo e Castro em 04/11/1962 onde comenta o livro do autor português: "Acabo de receber, gratamente, seus IDEOGRAMAS. E, desde o princípio, já se deflagra uma questão ou reação em cadeia: são eles de ler? Não e $\underline{\operatorname{sim}}$. Pois não são de ler e ver? E ainda não e sim, que há mais. E é ter. Mas ter é sim ou não? Quem, afinal, tem a poesia? E que é o que a poesia tem? Tem um não ou um sim? Quem sabe, na poesia, isto é, no poema, há de se ler, ver, ter, verter um ser - o próprio ser do poeta, senão (im ou não?) o ser próprio do $\underline{\text { objeto. }}$. Do objeto artístico - objetotem o tato do poeta que, atento, sente ao tato - um ato, o ato criador. Estranho totem, desalienado, não exclusivo do poeta (que é do rei?) e da sua grei e da sua lei mas, sim, compreensivo de outras gentes e outras terras, lado a lado, as mesmas. Alto teto, donde o pêndulo se precipita em círculos de tontura e aceleração de ritmos no fundo do poço ou, exatamente, à fonte alfabética. É como se, sobre o choque de sismos o poeta viesse da serra ao vale. Rolam os dados (hipnotismo?). O certo é que funciona o gerador - a máquinaimagem. E, do círculo aberto em cristal e arco-íris, o gesto poético traga novos perfis. Se a asa sem ar resiste e à casa sem sol é triste - edifício de ferro e cimento - água vem, água vai, e se faz troca ou dura pura. A casa, em si, fala, e há (ah!) luta e flor. E, porque, também há espinha dorsal, um livro monumento ergue-se por fim". (A carta de Pedro Xisto a E. M. de Melo e Castro foi publicada na revista eletrônica brasileira Zunái, na página http://zunai.com.br/post/56772592455/carta-de-pedroxisto-para-e-m-de-melo-e-castro) A respeito dessa carta, e da relação com Pedro Xisto, escreve o poeta português, no mesmo link: "Só mais tarde, em 1966, quando vim pela primeira vez ao Brasil e a São Paulo é que conheci pessoalmente o Pedro Xisto e com ele falei sobre o Haikai. Quando 
do prodígio: bases teóricas e antologia de textos-visuais portugueses dos séculos XVII e XVIII, e também em composições esparsas de Mário de Sá-Carneiro, Mário Cesariny, Jaime Salazar Sampaio ou Alexandre O'Neill). A estratégia adotada por Melo e Castro nesta coleção de poemas estabelece uma clara consonância entre disposição gráfico-espacial e referente: assim, no poema Pêndulo, letras e sílabas são distribuídas na página de modo a sugerir o movimento pendular (Figura 1); em Edifício, as letras que formam o poema são inseridas em linhas verticais e horizontais, simulando contornos de um prédio; em Ritmo, a variação gráfica do texto indica a alternância de tempos fortes e fracos do compasso musical, além de reforçar, visualmente, as relações de ambiguidade entre as palavras ritmo e riso.

\section{Figura 1}

A representação visual do significante do poema, nos Ideogramas de Melo e Castro, recorda as experiências de Guillaume Apollinaire ${ }^{2}$ nos Caligrammes (1918), como por exemplo na peça il pleut (Figura 2), em que os versos, dispos-

\footnotetext{
regressei a Lisboa levei comigo alguns poemas inéditos do Pedro Xisto que foram publicados no no 2 da Revista de Poesia Experimental (1966) e no no 1 da revista Operação (1967), de minha iniciativa. Hoje esta carta é um documento verdadeiramente notável e único, nas relações poéticas entre Portugal e Brasil, nesses anos de 60!"

2 Apollinaire é o autor de uma frase adotada como grito de guerra pelos concretistas: "il faut que notre intelligence s'habitue à comprendre synthético-ideographiquement au lieu de analyticodiscursivement" (in: Campos, Pignatari, Campos, 1975: 156).
} 
tos em linhas verticais e inclinadas, simulam a própria chuva - experiência que pode ter inspirado a composição pluvial / fluvial, de Augusto de Campos (Figura 3), com uma diferença metodológica clara: enquanto Apollinaire ${ }^{3}$ preserva o verso e o discurso sintático linear dentro da nova arquitetura semântica, Augusto de Campos rompe com a versificação e o pensamento gramatical, construindo seu poema com apenas duas palavras.

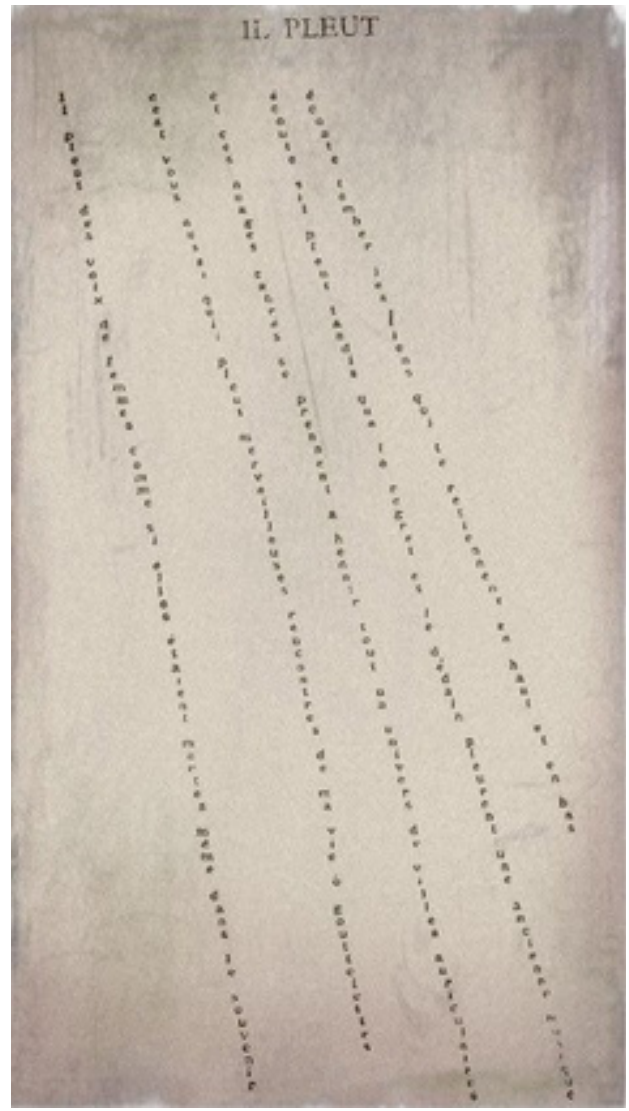

Figura 2

3 A esse respeito, escreve Haroldo de Campos: “É bem verdade que o 'caligrama' de Apollinaire se perde na pictografia, exterior, imposta (no poema com forma de objetos, na figuração artificial à composição); mas sua formulação teórica (...) é fecunda e profética" (in: Campos, Pignatari, Campos, 1975: 97). 
A relação mimética fundo / forma, no entanto, é apenas o aspecto mais superficial na apropriação do princípio do ideograma pelos poetas concretistas, que valorizaram, sobretudo, a técnica de justaposição ou montagem da poesia ideográfica chinesa e japonesa. "Nesse processo de composição" - dizem Fenollosa e Pound - "duas coisas conjugadas não produzem uma terceira, mas sugerem alguma relação fundamental entre ambas" (Campos, Pignatari, Campos, 1975: 96). "Em The cantos, de E. P., o ideograma é o princípio de estrutura presidindo a interação de blocos de ideias, que se criticam, reiteram e iluminam mutuamente" (idem), escreve Haroldo de Campos no texto Aspectos da Poesia Concreta. Prossegue o poeta e ensaísta brasileiro: "O isolamento de núcleos temáticos em cadeias de essências e medulas impõe a tomada de consciência do espaço gráfico como fator de organização do corpo do poema (vejam-se, nesse sentido, especialmente, os Cantos pisanos e a seção Perfuratriz de rochas, última publicada, de 1955)" (idem).

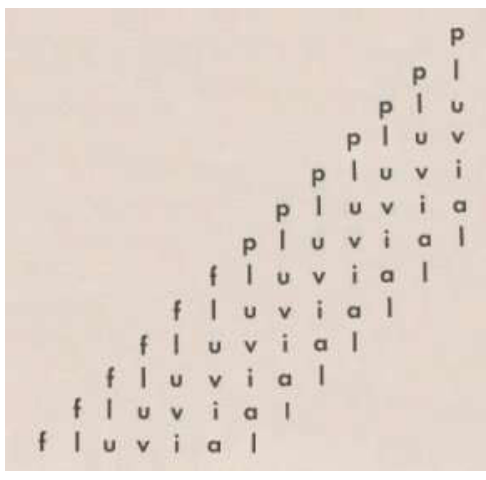

Figura 3

A poesia de Melo e Castro, apesar das evidentes aproximações que podem ser feitas com o ideograma - quanto à concisão, visualidade, ruptura com a sintaxe e com o discurso linear, substituído pela aglutinação de partículas semânticas em estruturas gráfico-espaciais ${ }^{4}$-, faz pouco uso da justaposição analógica de signos que caracteriza o ideograma; na maioria das composições de seu livro, como

\footnotetext{
4 Conforme escreveu o poeta português, "quase toda a Poesia Experimental Portuguesa produzida a partir da década de 60 se pode inscrever dentro de uma denominação geral de POESIA ESPACIAL, uma vez que as suas coordenadas visuais são dominantes" (Melo e Castro, Hatherly: 1981: 9). A expressão se justifica porque "é no campo das experiências visuais e espaciais do texto, considerado como matéria substantiva de que o poema se produz, que a pesquisa morfológica, fonética, sintática e semiológica se projetou e se projeta" (idem).
} 
é o caso de Pêndulo e Arco-íris, predomina o figurativismo icônico de Apollinaire, ou ainda experiências cinéticas que dialogam com a poesia visual do barroco português como é o caso de Tontura (Figura 4), composto de uma única palavra, que é fragmentada em diferentes sequências de letras, dispostas em círculos concêntricos. O poema solicita uma nova dinâmica de leitura para reproduzir, pelo movimento lúdico, o efeito desejado pela composição. Neste poema, assim como em outras peças de Ideogramas, é claro o uso de técnicas de combinação, permutação, anagrama e leitura labiríntica ${ }^{5}$ que permitem a multiplicidade de rotas de interpretação e construção do sentido, tema estudado por Umberto Eco em seu clássico livro Obra aberta, de 1962 (precedido por artigo de Haroldo de Campos, publicado em 1955 no jornal Diário de São Paulo).

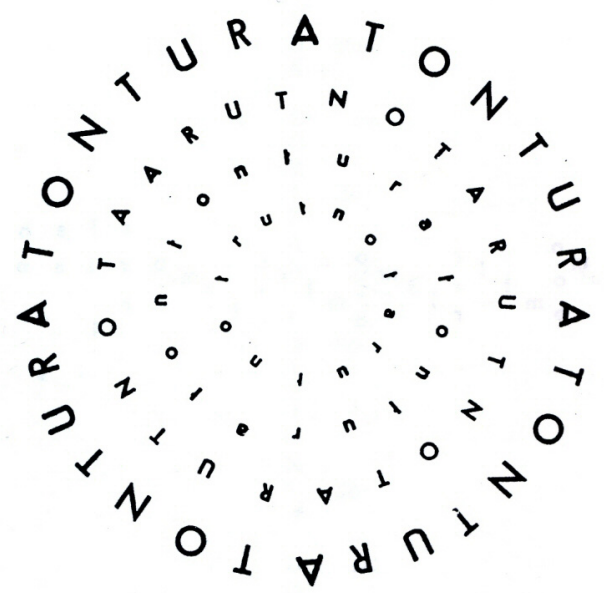

Figura 4

Uma composição curiosa do volume, que se aproxima do princípio da montagem analógica do ideograma, é o poema (sem título) que associa os termos antitéticos sim e não aos verbos ler, ver, ter e ser, alinhados em colunas verticais e dispostos em diferentes sequências (Figura 5). A formatação visual da peça, próxima ao abstracionismo, obedece a uma lógica estrutural e rítmica que dispensa a relação mimética entre fundo e forma. O leitor é convidado a percorrer o poema por diversas trilhas labirínticas, construindo múltiplas possibilidades de

\footnotetext{
5 A influência das técnicas de composição da poesia visual do barroco português na vanguarda experimental portuguesa foi abordada por nós no livro $A$ estética do labirinto: barroco $e$ modernidade em Ana Hatherly (Bauru: Lumme Editor, 2010).
} 
leitura: podemos pensar, nesse caso, no "ideograma como processo relacional, enquanto metáfora estrutural ${ }^{\prime \prime \prime}$.

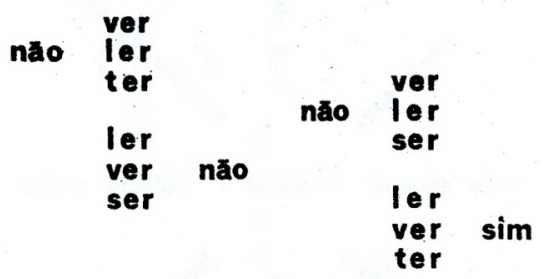

Figura 5

No ensaio Ideograma, anagrama, diagrama, Haroldo de Campos afirma que, no pensamento chinês, "os opostos não são excluídos, mas integrados numa interrelação dinâmica, mutuamente complementar" (Campos, 2000: 84). Isto significa que, em lugar da "lógica da identidade" típica da lógica ocidental, prevalece, no sistema de ideias chinês, uma "lógica da correlação", onde o interesse está "no interrelacionar dos signos (caracteres), não na substância" (idem, 8485). Ao silogismo de origem grega, baseado na "lógica da identidade", o pensamento chinês prefere a analogia. O poema de Melo e Castro, que entre o "sim" e o "não" perfila quatro verbos no infinitivo, sem sujeito (mesmo oculto), oferece ao leitor todas as possibilidades de analogia e, portanto, de construção de significados. O poeta português, diga-se de passagem, desconhecia, em meados da década de 1960, a poesia chinesa ou japonesa, e tomou conhecimento do princípio do ideograma por meio dos poetas concretistas brasileiros ${ }^{7}$, que por sua vez absorveram as reflexões de Fenollosa, Ezra Pound e Eisenstein sobre a escrita ideográfica. De modo distinto das experiências realizadas por Ana Hatherly no mesmo período, com os Mapas da imaginação e da memória (Lisboa: Moraes Editores, 1973), que dialogam com a materialidade da escrita chinesa e o seu

CAMPOS: $2000,66$.

7 Dois acontecimentos referidos por Melo e Castro antecedem o surgimento da Poesia Experimental: "primeiro, a rápida visita a Lisboa de Décio Pignatari, em 1956 (...), após o seu já histórico encontro com Gomringer; segundo, a publicação em 1962, pela Embaixada do Brasil em Lisboa, de uma pequena mas excelente compilação da Poesia Concreta do Grupo Noigandres" (Melo e Castro, Hatherly, 1981: 9). 
caráter caligráfico, Melo e Castro praticou uma abordagem mais conceitual do ideograma, com o filtro dos recursos da poesia visual barroca e da bagagem da poesia de vanguarda das primeiras décadas do século XX.

A obra visual de Melo e Castro ultrapassa o mimetismo icônico e aproxima-se de uma nova geometria da composição em obras posteriores, como a segunda coleção de Ideogramas (1966), os Cinéticos (também de 1966) e sobretudo os Infopoemas (1998), estes últimos realizados com programas de computador. 0 poema sem título que abre o caderno dos novos Ideogramas é formado por sete palavras entrecruzadas (coração / respiração / inspiração / expiração / espaço / braço / abraço), com as letras em diferentes corpos e fontes, dispostas num conjunto sem contornos discerníveis: o figurativismo cede vez à abstração e a leitura torna-se o terreno da combinação, da permutação e da ambiguidade (Figura 6):

$$
\text { [ de ideogramas - } 1966 \text { ] }
$$

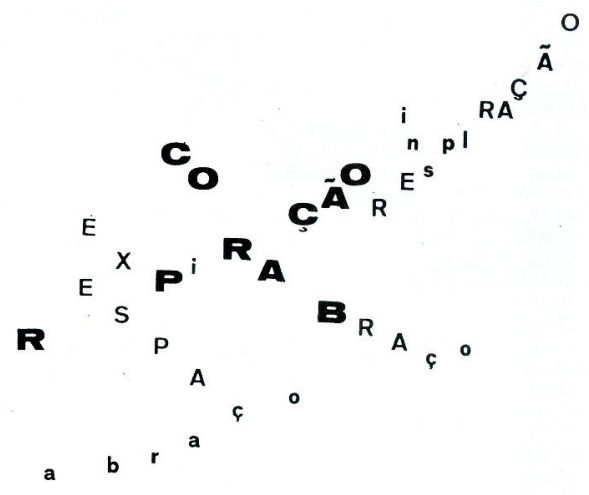

Figura 6

Em outra peça do ciclo, as palavras man, woman, name e amor são desmembradas e as letras, repetidas e recombinadas em diferentes sequências anagramáticas, formando imagens e sons puramente abstratos (Figura 7) - experiência radicalizada em outra peça, composta pela repetição de apenas duas letras, $s$ e $z$, combinadas e mescladas até a deformação e a mancha (Figura 8): 


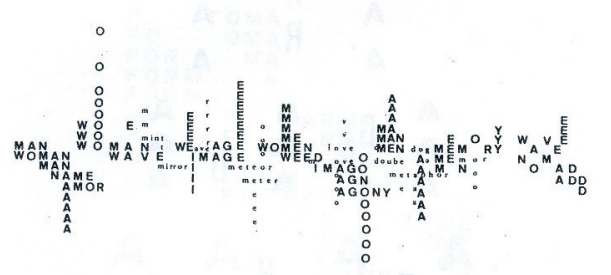

Figura 7

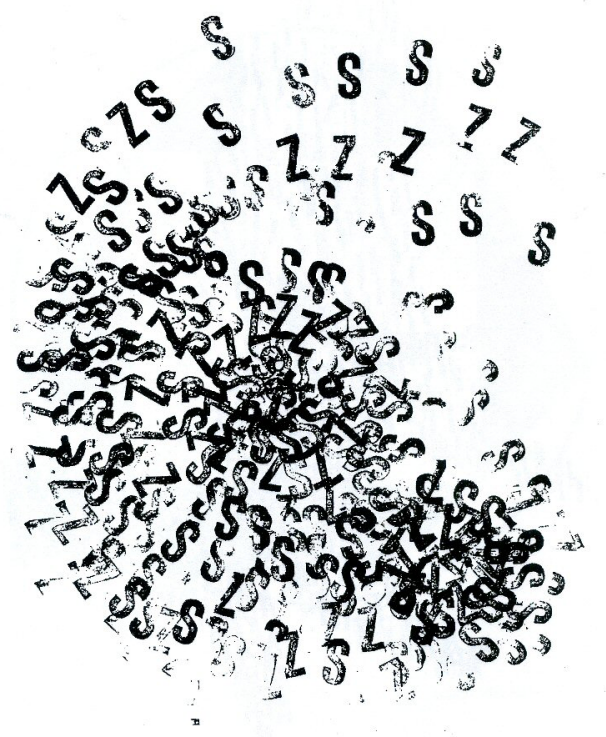

Figura 8

A série de poemas intitulada Cinéticos, como o próprio nome indica, é um conjunto de poemas visuais que simulam o movimento: diferentes versões de cada imagem gráfica (composta por desenhos geométricos e eventualmente também palavras, sílabas ou letras) são dispostas em sequências que recordam a linguagem cinematográfica. A peça dedicada ao silêncio, formada por cinco retângulos, duas cores (branco / preto) e uma única palavra (silêncio) é a que mais se aproxima do princípio do ideograma, tal como entendido por Fenollosa: o sentido da composição é construído pela relação entre as imagens, numa representação visual do som que se transforma em silêncio (Figura 9): 

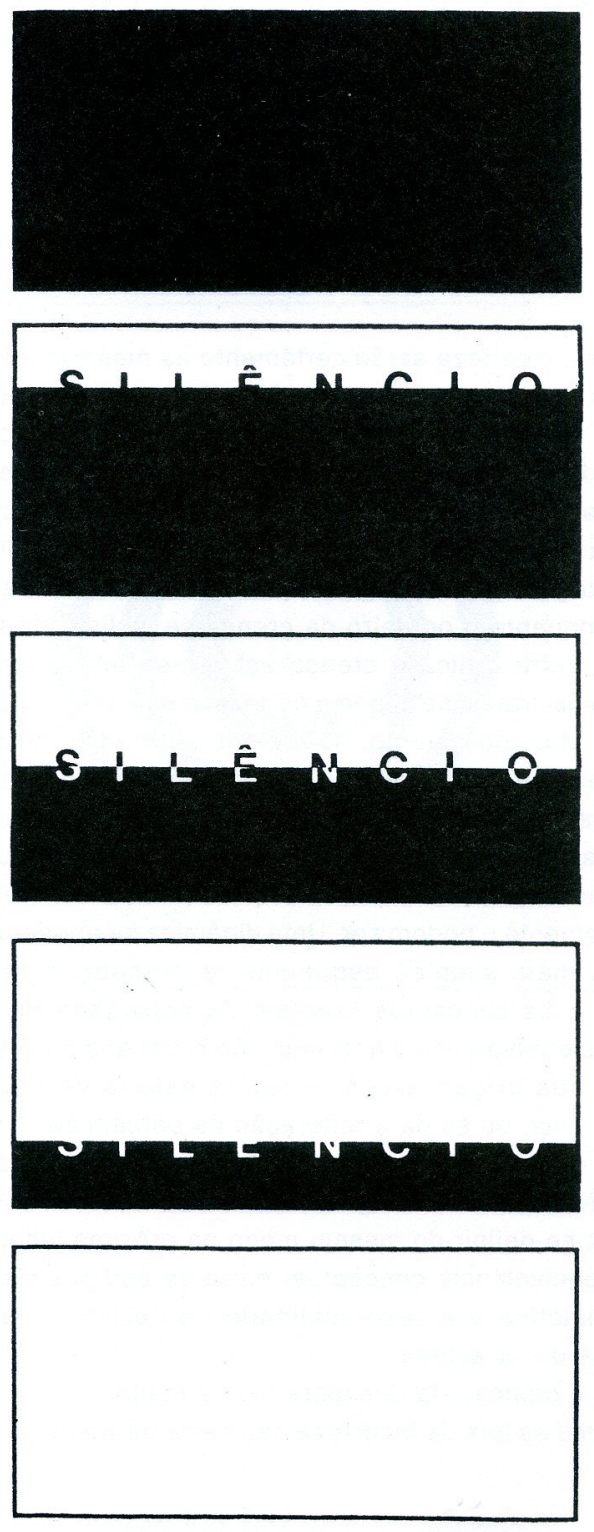

Figura 9 
Nos Infopoemas, cabe destacar as peças da sequência intitulada Transfilm, em que as letras são deformadas e convertidas em pontos, linhas, manchas e figuras puramente abstratas, desprovidas de qualquer valor semântico e possibilidade de leitura (Figura 9). Nessas composições, que dissolvem os limites entre literatura, pintura, tecnologia e grafismo, Melo e Castro obtém expressivos resultados plásticos, equiparáveis aos ruídos gráficos de seus ilustres antepassados, os mestres calígrafos japoneses:

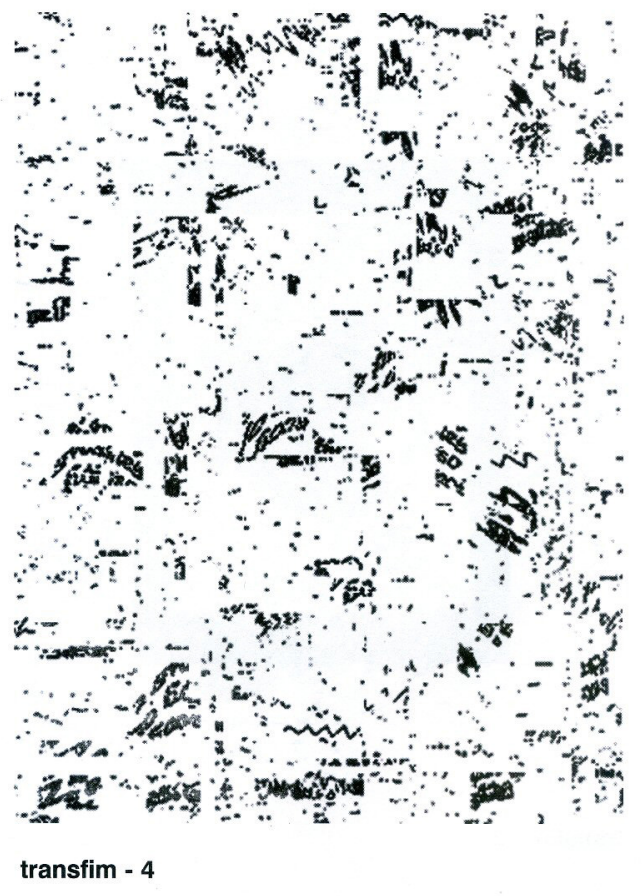

Figura 10

Diálogo explícito com a poesia japonesa será realizado na série Haiku erótico, conjunto de 14 poemas que integram o volume De entre o rigor e o excesso: um osso, publicado em 1994. Ao contrário do terceto adotado na maioria das tentativas ocidentais de adaptação desse gênero poético, Melo e Castro adota o quarteto (lembremos que o haicai japonês tradicional podia ser escrito em uma, duas, três ou quatro linhas, sendo o quarteto a forma adotada por Wenceslau de Moraes em suas pioneiras transposições do haicai para a língua portuguesa), sem medidas métricas fixas, embora as linhas, em geral, estejam próximas às 
redondilhas portuguesas ${ }^{8}$. Todas as peças da série são escritas em caixa baixa, sem pontuação, com raras rimas internas ("na onda anda", "negro loiro", "beijo eixo"), num estilo próximo ao de outras composições experimentais do poeta (como os poemas mais concisos do volume De corpos radiantes, de 1982). O autor português desconsidera as convenções clássicas do gênero, como o a presença do signo da estação do ano (o kigo), a referência ao local onde foi escrito o poema e, sobretudo, a ação, o movimento súbito que faz a ligação entre o céu (eternidade), o homem e a terra (mundo dos fenômenos). Melo e Castro não pretende niponizar a sua lírica, numa fácil aclimatação de flores de lótus, cerejeiras, templos silenciosos, samurais e outros elementos repetidos com certa frequência por poetas ocidentais que tentam reproduzir aquilo que imaginam ser o Japão, o haicai e o zen-budismo. O poeta português escolheu trabalhar a forma japonesa sem renunciar ao seu repertório cultural, à sua formação europeia; não quer convencer o leitor de que a sua sensibilidade está próxima à de Bashô e seus discípulos, nem fingir uma simplicidade que contrarie seu voluntário rebuscamento. Renunciando ao clichê, Melo e Castro realiza uma microlírica de extrema originalidade, a começar pela temática erótica, ausente no haicai japonês tradicional. Sua linguagem é fragmentária, elíptica, e as linhas se sucedem de maneira rápida, como em um videoclipe: "mamilos ilhas / do mar elástico / flores / na pele do peito" (idem, 177). A transformação do corpo humano em um mapa onde estão espalhados ilhas, mares e flores é um recurso metafórico próximo a um preciosismo barroco ${ }^{9}$; em outra composição, de aparente simplicidade, a figura empregada é a metonímia: "fundo e claro / o obscuro fluxo / canto do olho aberto" (idem). A (quase) ausência de rimas é compensada, na maioria das peças, por jogos sonoros de caráter aliterativo ("a saliva sabe", "vulva / volume vago", "nulo de nada") ou ainda por assonâncias ("do sol o toque", "voo no ritmo", "das asas duplas"). Em todos os micropoemas da série, a pedra-de-toque é a representação do ato erótico a partir de associações com elementos da na-

8 Consideramos aqui a redondilha menor, de cinco sílabas, e a redondilha maior, de sete sílabas, contadas até a última sílaba tônica, conforme a codificação de Castilho. Na versificação japonesa, assim como ocorria nas cantigas galego-portuguesas, a contagem de sílabas desconsiderava a acentuação final, fato observado e comentado por Álvaro Faleiros em seu livro Tradução e significância nos caligramas de Apollinaire: o espaço gráfico, o metro e a textura fônica (São Paulo: EDUSP, 2003).

9 Composição similar a esta, no procedimento, é o haicai "na pele do deserto / areia movediça / cetim / de dedos cactus" (idem). 
tureza, que materializam o amor em sua dimensão animal; como inesperado clímax (anticlímax?), o último terceto anula as regras do jogo, numa figuração deliberadamente abstrata do êxtase: "total orgasmo / nulo de nada / luz / sobre a iluminação", linhas que recuperam palavras do vocabulário zen-budista, mas reconfiguradas em outro campo de referências: na erotografia poética de Melo e Castro é pelo corpo que o sentido vem. 


\section{Referências}

AKIKO, Yosano. Descabelados. Brasília: Editora Universidade de Brasília, 2007. Tradução: Donatella Natili e Álvaro Faleiros.

CAMPOS, Haroldo de. Ideograma. São Paulo, Edusp, 2000.

CAMPOS, Augusto e Haroldo de e PIGNATARI, Décio. Teoria da poesia concreta. São Paulo: Duas Cidades, 1975.

DANIEL, Claudio. A estética do labirinto: barroco e modernidade em Ana Hatherly. Bauru: Lumme Editor, 2010.

FALEIROS, Álvaro. Tradução e significância nos caligramas de Apollinaire: o espaço gráfico, o metro e a textura fônica (São Paulo: EDUSP, 2003).

HATHERLY, Ana. Mapas da imaginação e da memória. Lisboa: Moraes Editores, 1973. . A experiência do prodígio - bases teóricas e antologia de textos-visuais portugueses dos séculos XVII e XVIII. Lisboa. Imprensa Nacional - Casa da Moeda, 1983.

e MELO E CASTRO, E. M. PO.EX - Teóricos e documentos da poesia experimental portuguesa (com E. M. de Melo e Castro). Lisboa: Moraes Editores, 1981. MELO E CASTRO, E. M. Antologia efémera. Rio de Janeiro: Lacerda editores, 2000. 